Research Article

\title{
Grid Integration of a Residential PV-based Hybrid Renewable Energy System Using High-Frequency Multi-winding Transformer
}

\author{
Mohammad Jafari ${ }^{*}$, Zahra Malekjamshidi \\ University of Technology Sydney, 15 Broadway, NSW 2007, Sydney, Australia; E-Mails: \\ mohammad.jafari@uts.edu.au; z malekjamshidi@yahoo.com
}

* Correspondence: Mohammad Jafari; E-Mail: Mohammad jafari1@yahoo.com

Academic Editor: Joaquin Alonso-Montesinos

Special Issue: Photovoltaic Solar Systems and Solar Thermal Plants

Journal of Energy and Power Technology

2020 , volume 2 , issue 3

DOI: $10.21926 /$ jept.2003014
Received: June 13, 2020

Accepted: July 31, 2020

Published: August 05, 2020

\begin{abstract}
In this paper, a topology of a residential hybrid renewable energy system based on a highfrequency multi-winding transformer is introduced and analyzed. The system includes a PV and a wind-turbine as renewable energy sources, a battery as energy storage and their energies are integrated through a high-frequency transformer. In fact, the transformer integrates the energies in a magnetic form and also isolates the system inputs and outputs. The integrated output from renewables and battery is a DC high-voltage and is transferred to a grid-connected inverter to supply the residential loads and also injected to the grid on request. A phase shift control technique is used to control the power flow between the sources, storage and loads. Detail of the control system is presented and also validated through experimental tests.
\end{abstract}

\section{Keywords}

Phase shift control; photovoltaic panel; residential load; wind turbine

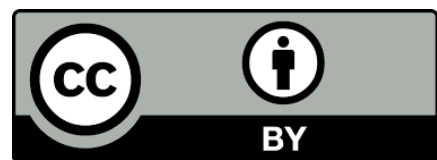

(C) 2020 by the author. This is an open access article distributed under the conditions of the Creative Commons by Attribution License, which permits unrestricted use, distribution, and reproduction in any medium or format, provided the original work is correctly cited. 


\section{Introduction}

Multiport converters have been an attractive research topic over the past decade due to their application in the integration of several renewable energy sources into a single power processing unit. Therefore, a large number of topologies for the integration of renewable energy systems has been introduced in the literature so far [1-9]. The proposed topologies can be classified as the topologies operate based on the series or parallel connection of small conversion cells [10], the time-sharing concept [11-13] and magnetic flux additivity [14]. Furthermore, some of them have the property of bidirectional power flow between the connected ports, while others are unidirectional only [15]. Among the proposed topologies, those are based on magnetic-coupling through a multi-winding transformer have attracted more attention due to their excellent features in terms of flexibility, safety and isolation and operational power range. This provides an isolation between the ports and facilitates connecting several sources having substantially different operating voltages thanks to the transformer turns ratio [16]. On the other hand, a more straightforward power flow control can be achieved by using a phase-shift control technique [1719]. A complete study on the magnetically coupled multiport converters has been presented in [1620]. It should be noted that the system operation and design of multi-winding high-frequency transformer become very complex in the case of a large number of windings [21-24]. A magnetically coupled converter with two inputs and one output is presented in [25] where instead of combining input dc sources in electric form, they are combined in magnetic form by adding up the produced magnetic fluxes together using the magnetic core of the multi-winding transformer. The power flow in the proposed converter has been drawn from two different dc sources and delivered to the load individually and simultaneously [16]. The converter is able to accommodate voltage variations of the sources by using the current-fed $\mathrm{H}$-bridge converters. However, the topology is not able to maintain a bidirectional power flow and the current stress of the switching devices is high [16]. A three-port converter was proposed in [26] to couple a fuel cell and a battery system and the topology was also recommended in [27] for application in uninterruptible power supply (UPS). Using batteries along the renewable energy sources increases energy management flexibility [27, 28]. However, many technical points need to be considered when using batteries as energy storage [29]. As another application, a three-port converter is introduced using two current-fed ports to interface several energy storage elements such as batteries and supercapacitors [30]. As a recent application, the magnetically coupled multiport converter is used in a hybrid energy system for a residential house $[17,19]$. The proposed topology enables the system to operate based on the different control techniques and energy management scenarios [16].

The common technique of coupling converter ports to the multi-winding transformer employs the $\mathrm{H}$-bridge dc-ac converters to generate a high-frequency rectangular waveform from the input $\mathrm{dc}$ voltage as discussed in more detail in [16, 31, 32]. The power flow control then can be realized by applying leading or lagging phase shift between the generated waveforms. The topology is suitable for medium-power applications (a few kilowatts) and the main advantages are simultaneous bidirectional power transfer between any input to any output, the possibility of softswitched operation for all coupled $\mathrm{H}$-bridges, galvanic isolation between the input and outputs, capability of matching different voltage levels using transformer turns ratio and centralized control [16]. Furthermore, less conversion stages can be achieved when the power is flowing from the renewable sources to the storage device compared to the conventional case of using a common ac 
or dc electrical bus as presented in Figure 1. As can be seen in Figure 1(a) four conversion stages and two transformers are in the power transfer path from PV array to the storage device. In contrast, this can be reduced to only two converter units and multi-winding transformer in as presented in Figure 1 (b) which leads to a higher efficiency. However, there are some disadvantages such as a large number of switching devices, limited soft-switched region when operating with wide input voltage ranges and complexity of transformer design $[16,17]$. The problem of soft-switching range in the case of using variable dc sources as the input source can be reduced by applying duty cycle control to the generated waveforms or using current-fed $\mathrm{H}$-bridge converters instead of simple $\mathrm{H}$ bridges [33]. In [34], the authors studied some other bridge converters with the possibility of using in the phase-shift converters. To analyse the multiport phase shift converters, the multiport topology can be decomposed into the simple dual active bridge (DAB) converter topologies as is discussed in [6, 16, 35]. The DAB converter was proposed by Kheraluwala and Divan in [36] and a more detailed analysis was provided in [37]. The topology has been widely studied in the literature and modified considerably over the last decade. The improvement in the switching conditions of the bridge converter is studied in $[38,39]$ and the problem of circulating reactive power and possible solutions have been studied $[40,41]$.

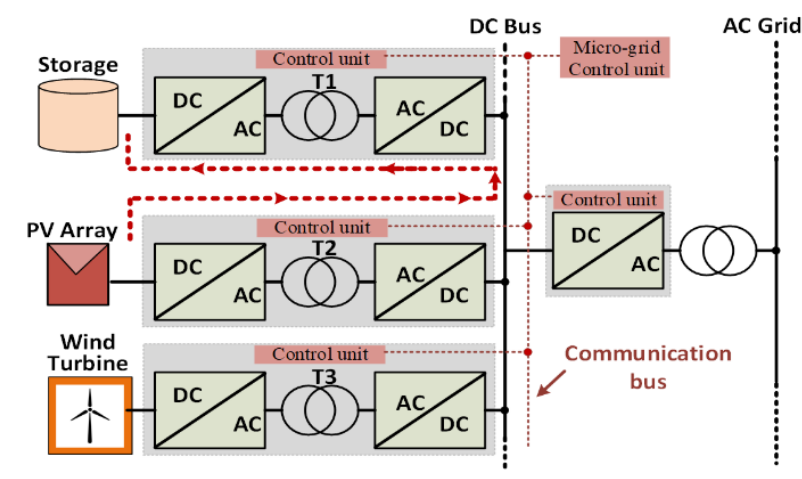

(a)

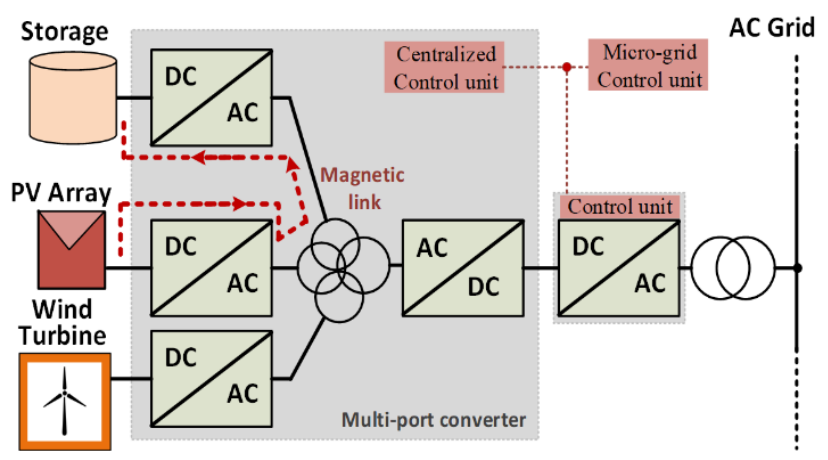

(b)

Figure 1 Structure of a hybrid renewable energy system, (a) without, and (b) with the multi-winding transformer as a magnetic link

In this paper, a multiport phase shift converter topology based on a multi-winding high-frequency transformer for integrating a PV system, a wind turbine generator and a battery is introduced to supply a set of grid-connected domestic loads. The system is designed to transfer the power from renewable energy sources to the battery, load and grid. However, the power can be supplied from the grid to the battery in the reverse direction when is required, which increases the flexibility of the system compared to the other proposed multiport converter topologies. The system operation principle is discussed in detail and the control technique is also studied. Numerical simulation of the proposed topology and control technique is carried out using PSIM software and the experimental tests are conducted to show the validity of system operation and the proposed control techniques.

\section{Topology of the Proposed Converter}

The topology of the proposed Multiport converter is presented in Figure 2. As illustrated in the figure, the converter topology contains four $\mathrm{H}$-bridge dc-ac converters linked to a multi-winding transformer at one side and to a dc source at the other side. The $\mathrm{H}$-bridge converter in port one is connected to a PV generation system, port two to a wind turbine generator, port three to a battery 
and port four to a high-voltage dc bus followed by a single-phase inverter. In this structure, the transformer core is used as a magnetic coupling bus to transfer the power between the converter ports in a magnetic form $[20,21]$. The main advantage of the system that power ports having different operating voltages are easily matched by transformer turns ratios and also are electrically isolated and their relationship is only in the magnetic form [16]. As presented in the figure by arrows on the magnetic core, the power flows mainly from the PV system and wind turbine to the battery and inverter ports, however a bidirectional; power flow also can be realized between the battery and inverter port. The power flow in this system can be controlled by a phase shift technique as studied in detail in $[16,42]$. The $\mathrm{H}$-bridge converter in port four is connected to a high-voltage dc linked as the dc voltage is going to be changed to a single-phase ac voltage by the single-phase inverter $(220 \mathrm{Vrms}, f=50 \mathrm{~Hz}$ ). The generated ac voltage then can be supplied to the domestic loads or transferred to the grid as parallel link. The power also can be supplied by the power to the battery when the inverter is operating as a rectifier if the system is designed to operate as an uninterruptable power supply (UPS). To analyse the power flow in the system, the system can be simplified by using the cantilever model of the multi-winding transformer. The multiport converter with $\mathrm{N}$-port system can be decomposed into $\mathrm{N}(\mathrm{N}-1) / 2$ two-port converter as illustrated in Figure $3[15,16]$.The $\mathrm{dc}$ sources and the $\mathrm{H}$-bridge converters are combined and presented as voltage source with a rectangular high-frequency waveform for the sake of simplicity. The structure can be simplified further, as presented in Figure 3 where all the parameters at the transformer windings in port two, three and four are referred to the winding in port one and the magnetizing inductance is neglected as it has no influence on the power flow. As can be seen, the resultant structure shows that the four-port converter topology can be decomposed in several dual active bridge converter. Therefore, the total power flows from each converter port can be obtained by summation of power flows to each individual port, referring to the simplified model in Figure 3. The power flow equations in the proposed converter can be written as

$$
\left\{\begin{array}{c}
P_{1}+P_{2}+P_{3}+P_{4}=0 \\
P_{1}=P_{12}+P_{13}+P_{14} \\
P_{2}=P_{21}+P_{23}+P_{24} \\
P_{3}=P_{31}+P_{32}+P_{34} \\
P_{i j}=-P_{j i} \text { for } i, j=1,2,3,4
\end{array}\right.
$$

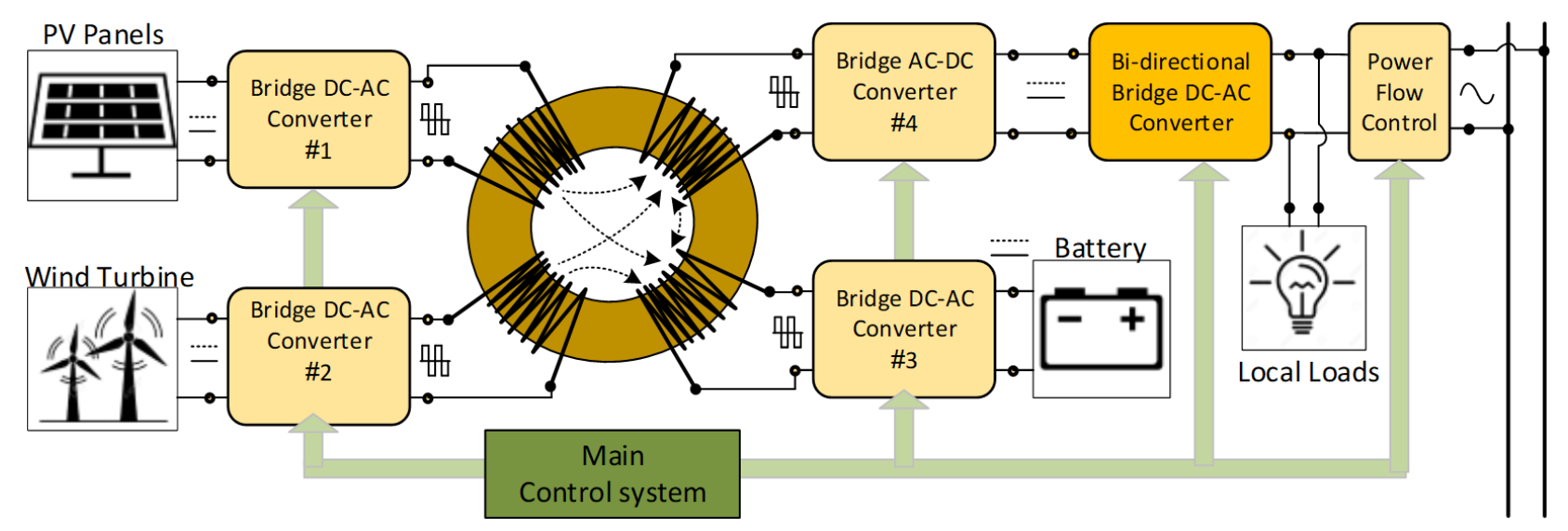

Figure 2 Topology of the proposed hybrid renewable energy system including the multiport phase-shift converter and grid-connected inverter 


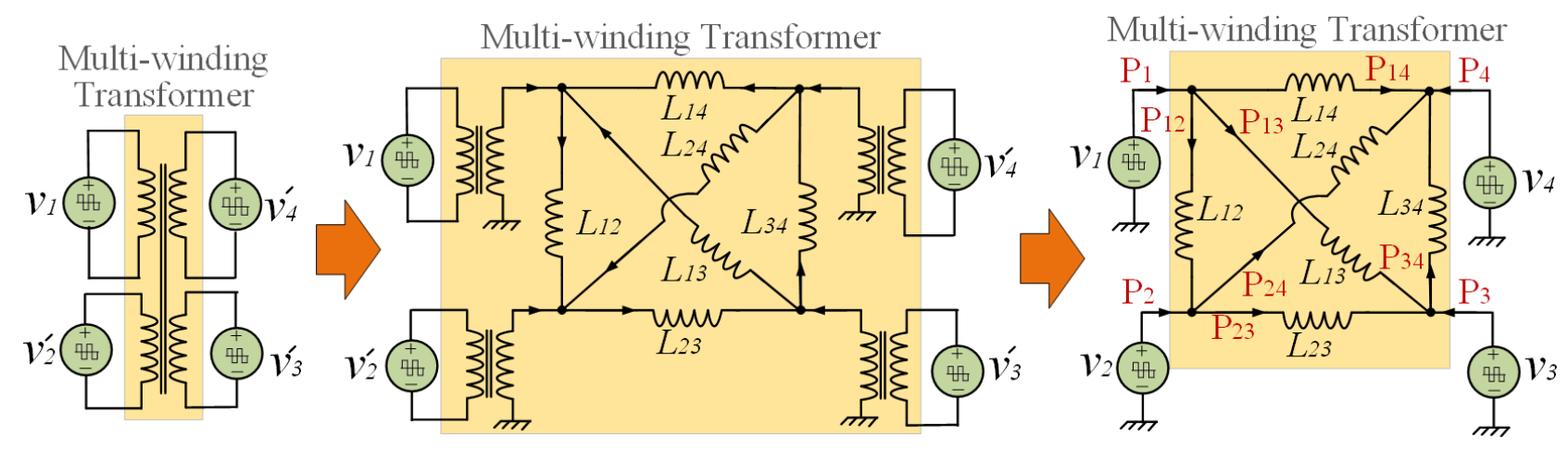

Figure 3 Simplified model of the four-port converter by simplifying the multi-winding transformer using cantilever model

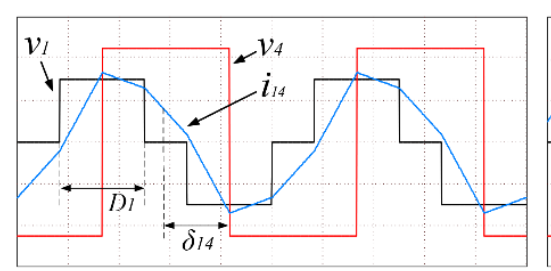

(a)

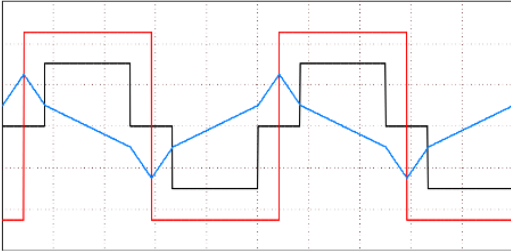

(b)

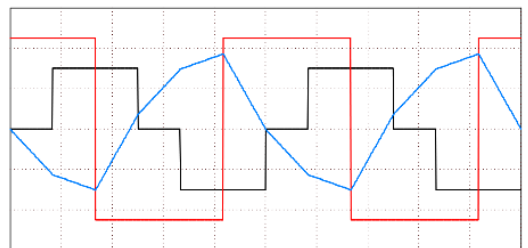

(c)

Figure 4 The waveforms of voltage and current of port one and four in the transformer winding for three cases of (a) $v_{1}$ is lagging $v_{4},(b) v_{1}$ and $v_{2}$ are in phase and (c) $v_{1}$ is leading $v_{2}$ where duty cycle of $v_{1}\left(D_{1}\right)$ and phase shift angle are presented.

To control the amount and direction of power flow, the generated rectangular waveforms are phase-shifted from each other by controlled angles, as presented in Figure 4 for the waveforms of the PV and inverter ports. The angles are named as $\delta_{14}$ for controlling the power flows from PV to the inverter port, $\delta_{24}$ from wind turbine to the inverter port, $\delta_{13}$ PV to the battery, $\delta_{23}$ from wind turbine to the battery port and $\delta_{34}$ for the battery to the inverter port. The phase shift $\delta_{\mathrm{ij}}$ is positive when the voltage in port $i$ lags the reference voltage in port $j$ and negative when it leads the reference. The voltage of the inverter-linked winding is presented as $v_{4}$ does not have any duty cycle control and is selected as the reference due to its constant amplitude for convenience and the other generated waveforms have their duty cycles and phase shift angles defined with respect to $v_{4}$. The power flows from port $i$ to port $j$ presented as $P_{i j}$ where $i$ represents the waveform in port $i$ related to the PV, battery or wind turbine. The voltage waveforms are duty cycle controlled at these ports. The index $j$ represents the port four where the waveform's duty cycle is constant and equal to one $(D=1)$. The transferred power $P_{i j}$, then can be determined according to the range of phase shift angle $\delta_{i j}$ as

$$
P_{i j}=\frac{V_{i} V_{j}}{\omega L_{i j}} D \delta_{i j} \text { for }\left|\delta_{i j}\right| \leq \frac{\pi}{2}(1-D)
$$

and for another range of phase shift angle can be determined as

$$
P_{i j}=\frac{V_{i} V_{j}}{\omega L_{i j}}\left[\delta_{i j}\left(1-\frac{\delta_{i j}}{\pi}\right)-\operatorname{Sign}\left(\delta_{i j}\right) \frac{\pi}{4}(1-D)^{2}\right] \text { for } \frac{\pi}{2}(1-D)<\left|\delta_{i j}\right| \leq \frac{\pi}{2}
$$


where $V_{i}$ is the dc voltage in port $i, V_{j}$ the dc voltage in port $j, \omega$ the frequency of waveforms, $L_{i j}$ the summation of leakage inductance in windings $i$ and $j$ and $D$ duty cycle in the waveform of port $i$ as presented in Figure 4(a). On the other hand, the power flow between the two ports such as PV or wind turbine to the battery port where both waveforms have duty cycle controlled can be presented as

$$
\begin{gathered}
P_{i j}=\frac{V_{i} V_{j}}{\omega n L_{i j}}\left[\delta_{i j}\left(1-\frac{\delta_{i j}}{\pi}\right)-\operatorname{Sign}\left(\delta_{i j}\right) \frac{\pi}{4}\left(1-D_{i}\right)^{2}-\operatorname{Sign}\left(\delta_{i j}\right)\left(1-D_{j}\right)^{2}\right] \\
\operatorname{for} \frac{\pi}{2}\left(2-D_{i}-D_{j}\right)<\left|\delta_{i j}\right| \leq \frac{\pi}{2} \\
P_{i j}=\frac{V_{i} V_{j} D_{j}}{\omega n L_{i j}}\left[\frac{\operatorname{Sign}\left(\delta_{i j}\right) \frac{\pi}{2}\left(D_{i}-D_{j}\right)+\delta_{i j}+}{D_{j}}\left[\operatorname{Sign}\left(\delta_{i j}\right)\left(-\frac{\pi}{4}\right)\left(D_{i}^{2}-D_{j}^{2}\right)+D_{i} \delta_{i j}-\operatorname{Sign}\left(\delta_{i j}\right) \frac{\delta_{i j}^{2}}{\pi}\right]\right] \\
\text { for } \frac{\pi}{2}\left|\left(D_{i}-D_{j}\right)\right|<\left|\delta_{i j}\right| \leq \frac{\pi}{2}\left(2-D_{i}-D_{j}\right)
\end{gathered}
$$

and for another range of phase shift angle can be determined as

$$
P_{i j}=\frac{V_{i} V_{j} D_{i} D_{j}}{\omega n L_{i j}\left(\max \left(D_{i}, D_{j}\right)\right)} \delta_{i j} \text { for }\left|\delta_{i j}\right| \leq \frac{\pi}{2}\left|D_{i}-D_{j}\right|
$$

where $D_{i}$ and $D_{j}$ are the duty ratio of $v_{i}$ and $v_{j}$ and $v_{i} / D_{i}=v_{j} / n D_{j}$ and $n=N_{j} / N_{i}$. The waveforms frequency is kept constant and the leakage inductance of the transformer windings are utilized as the main energy transfer elements $[16,42]$. A dc conversion ratio can be defined between the converter ports as

$$
d=\frac{V_{i}}{n V_{j}}
$$

where $n=N_{\mathrm{j}} / N_{\mathrm{i}}$ is the transformer turns ratio, $N i$ and $N j$ are the numbers of turns of the transformer windings in ports $i$ and $j$, respectively. Therefore, to analyze the four-port converter, the DAB converter topology should be considered as a basic step. In this topology, a full range of soft switching operation is achievable when $d=1$, which means an equal volt-second product of the voltage waveforms applied to the all transformer winding [24, 33]. In a lossless idealized circuit, the maximum power flow between the ports can be determined from $\partial P_{i j} / \partial \delta_{i j}=0$ which results a maximum power at $P_{i j}=\pi / 2$ as illustrated in Figure 5 (a). However, the phase shift angles greater than $\pi / 2$ results in an excessive reactive power as can be seen in Figure 5 (b) and therefore, the phase-shift is practically limited to less than $\pi / 2$ [42].

\section{Analysis of Control System}

The power flow equations in (2)-(6) show that the duty cycle and phase shift angle are the main elements that can be used as control variables. To discuss the control technique of the proposed converter, the simplified model of the phase shift converter facilitates the analysis. A main issue 
related to the PV and wind turbine generator as renewable energy sources is the inherent intermittency and uncertainty in their energy generation. Therefore, the generated electrical energy is variable and there is not a constant operation point to set the converter ports. As a result, the converter operating point in the PV and wind turbine ports needs to be adjusted according to the maximum available energy at any time. The process is known as maximum power point tracking (MPPT) in the PV and wind turbine converter ports. On the other hand, the extracted electrical power from renewable energy sources should be controlled constantly and follows the load demand and the grid conditions and standards. In this paper, to realize the MPPT, the duty cycle of the switching devices in the $\mathrm{H}$-bridge converters has been used as a control variable. On the other hand, the phase shift angle between the generated ac voltages at the converter ports is used to control the power flow between the converter ports. Therefore, the duty cycle control system should be designed to operate independently of the phase shift controller. In theory, arbitrary power flow in the system can be realized by a unique set of phase shifts [16]. In the system proposed in this paper, there are multiple control objectives. The power flow control scheme aims to control the power flow between the ports while regulating the dc bus voltage of the port. Figure 6 illustrates the designed control system containing the control variables, reference signals provided by the master controller and the control loops. The proportional-integral (PI) controllers have been used in the control loops to regulate the dc voltage and realize the MPPT operation. The PI controller transfer function are presented as

$$
G_{C}(S)=K_{p}+\frac{K_{i}}{S}
$$

where $K_{p}$ and $K_{i}$ are the proportional and integral control coefficients and in this paper are set as 0.01 and 0.56 respectively. The power flow control in each converter port can be designed to regulate the voltage according to the provided reference signal. As voltage-type energy sources like wind turbine and PVs have a variable operating voltage, a power control strategy can be used as an equivalent of current control due to the slow change of the operating voltage of the source compared to the control bandwidth [16] and the dynamics of the power control loop is mainly determined by the port current. Therefore, the dynamics of the voltage control loop can be ignored in the control design process and it is regarded as the relatively constant value represented by a gain in the control loop. Following this strategy, the power flow between the ports can be controlled by a proper selection of the phase shifts of the high-frequency voltages linked to the transformer windings. To reduce the control conflicts between the two variables (duty cycle and the phase shift), the dynamic response of the power flow control loop is designed to operate faster than the voltage control loop by designing proper controllers and adjusting $k_{p}$ and $k_{i}$. The proportional and integral control coefficients are determined based on the required crossover frequency $\left(\omega_{c}\right)$ and the phase margin $\left(\varphi_{m}\right)$ of the voltage and power control loops. Considering the PI controller transfer function as

$$
\begin{gathered}
C(j \omega)=K_{P}+\frac{K_{I}}{j \omega}=K_{P}-j \frac{K_{I}}{\omega} \\
|C(j \omega)| \angle \theta=|C(j \omega)|[(\cos (\theta)+j \sin (\theta))]
\end{gathered}
$$


Then the design problem is to find $K_{P}$ and $K_{l}$ for a chosen crossover frequency $\left(\omega_{c}\right)$ and phase margin $\left(\varphi_{m}\right)$ such that

$$
C\left(j \omega_{c}\right) G\left(j \omega_{c}\right)=1 \angle\left(180+\phi_{m}\right)
$$

From (10), we can find the following equations

$$
\begin{gathered}
\left|C\left(j \omega_{c}\right)\right|=\frac{1}{\left|G\left(j \omega_{c}\right)\right|} \\
\angle C\left(j \omega_{c}\right)=\theta=180+\phi_{m}-\angle G\left(j \omega_{c}\right)
\end{gathered}
$$

Finally, from (9) and (11) the values of controller coefficient can be determined as

$$
\begin{gathered}
K_{P}=\left|C\left(j \omega_{c}\right)\right| \cos (\theta)=\frac{\cos (\theta)}{\mid G\left(j \omega_{c}\right)} \\
-\frac{K_{I}}{\omega_{c}}=\left|C\left(j \omega_{c}\right)\right| \sin (\theta)=\frac{1}{\left|G\left(j \omega_{c}\right)\right|} \sin (\theta) \\
\Rightarrow K_{I}=\frac{-\omega_{c} \sin (\theta)}{\left|G\left(j \omega_{c}\right)\right|} \\
\theta=180+\phi_{m}-\angle G\left(j \omega_{c}\right)
\end{gathered}
$$

and $G\left(j \omega_{c}\right)$ is the open-loop transfer function of the voltage or power control loops. On the other hand, to reduce the conflict between the control loops in different converter ports, the dynamic response of the power control loops has been designed to operate in different speeds according to the nature and characteristics of the connected source, as presented in Figure 7. As can be seen, the crossing frequency of wind turbine control loop is about $200 \mathrm{~Hz}$ as the slowest source, PV equals $1.2 \mathrm{kHz}$, and the battery as $30 \mathrm{kHz}$ as the fastest source. The duty cycle control loops have the bandwidths less than $30 \mathrm{~Hz}$ for all three converter ports. At the inverter side, the control section of should be designed to provide proper values of the active and reactive power to the utility grid. Figure 8 (a) shows the control system designed for the grid-connected inverter. By using this control system, the inverter output current compensates the leading or lagging current of the load (reactive element of the load power) to have a unity power factor at the grid-connected point. This is possible as referring to the current reference presented in Figure 8 (b) which shows that the grid current basically depends on the load and inverter currents $\left(i_{g}=i_{O}-i_{L}\right)$. To control the output voltage of the inverter, the grid voltage is transformed into the equivalent direct-quadrature $(d-q)$ synchronous reference frame with respect to the required output current angular speed. Therefore, the voltage elements aligned with the $d$-axis and q-axis determined the active and the reactive power injected by the inverter, respectively. The active power is almost equal to the power generated by the input sources or received from the battery. Therefore, to control the active power extracted from the sources, the difference between the dc high-voltage at the inverter input ( $\left.V_{H V S}\right)$ and the reference value ( $V_{\text {HVS }}^{*}$ ) is translated to the $d$ component of the output voltage as presented in Figure 8 (a). 

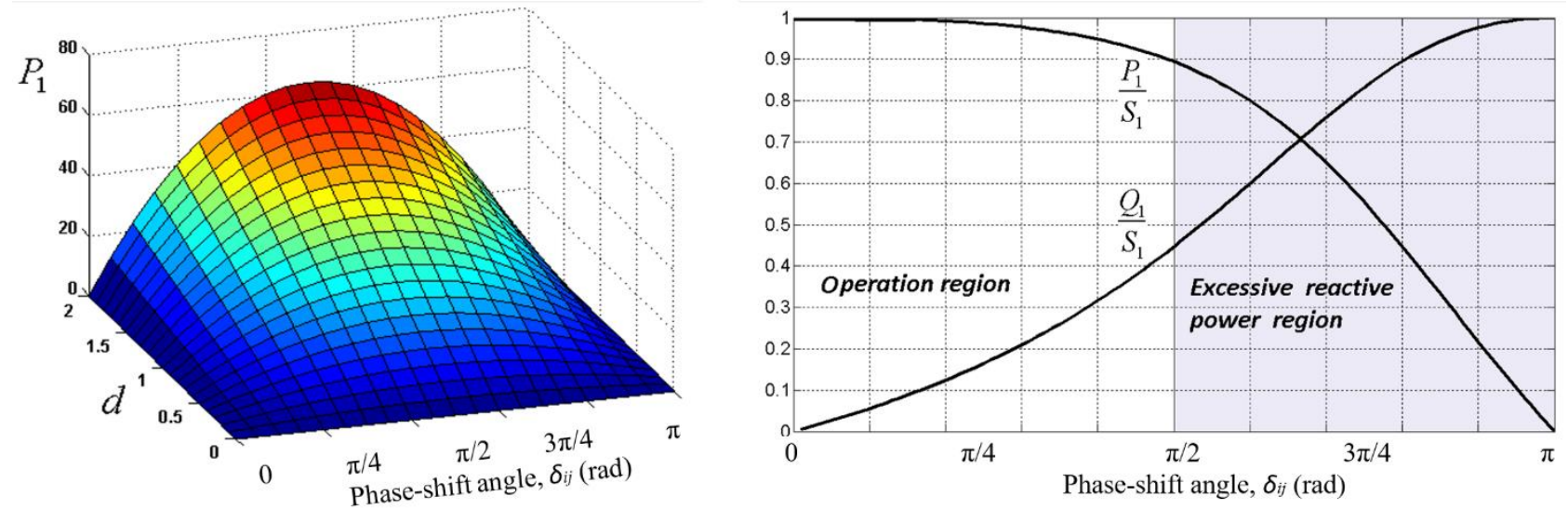

Figure $\mathbf{5}$ (a) the active power flow between two ports as a function of phase shift angle and (b) the active and reactive transferred power as a function of phase shift angle

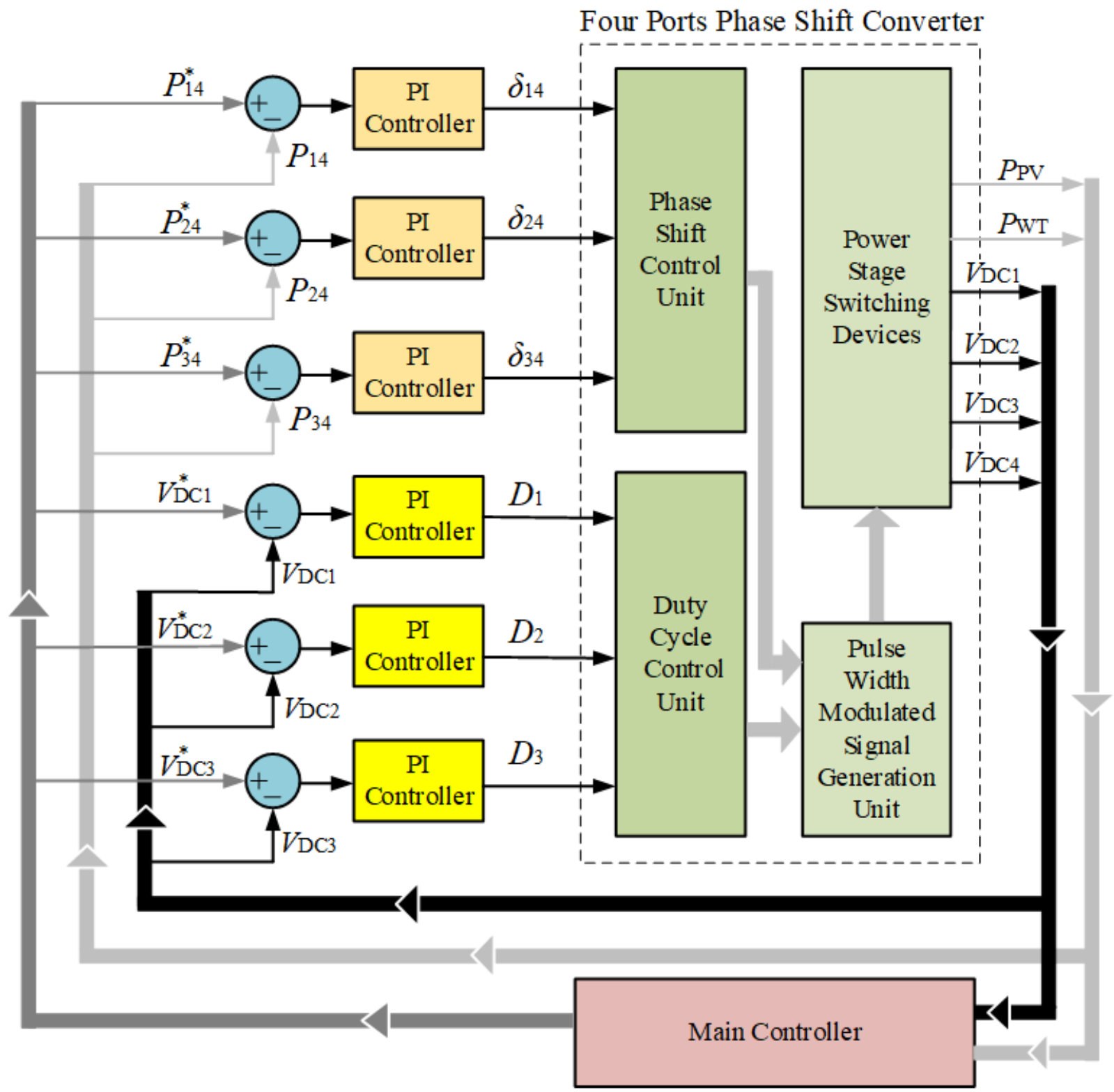

Figure 6 The control system for multiport converter in the proposed system 


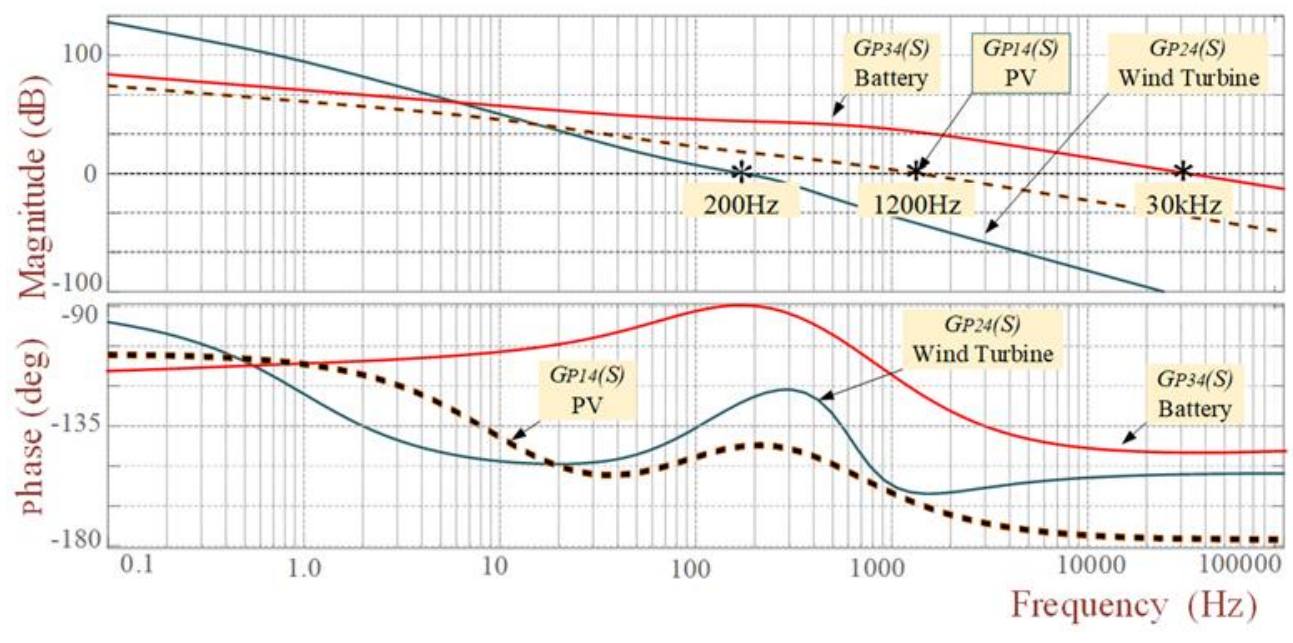

Figure 7 The magnitude and phase Bode diagrams of the power control closed-loop transfer functions

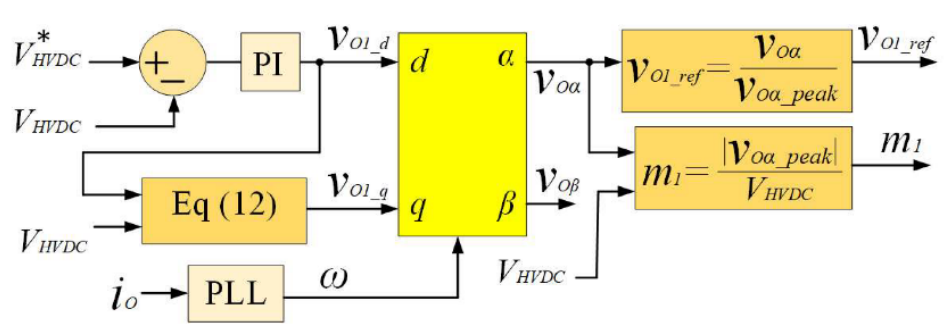

(a)

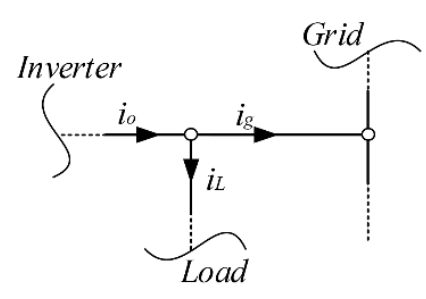

(b)

Figure 8 (a) The control system for the grid-connected inverter and (b) current direction reference in the inverter output

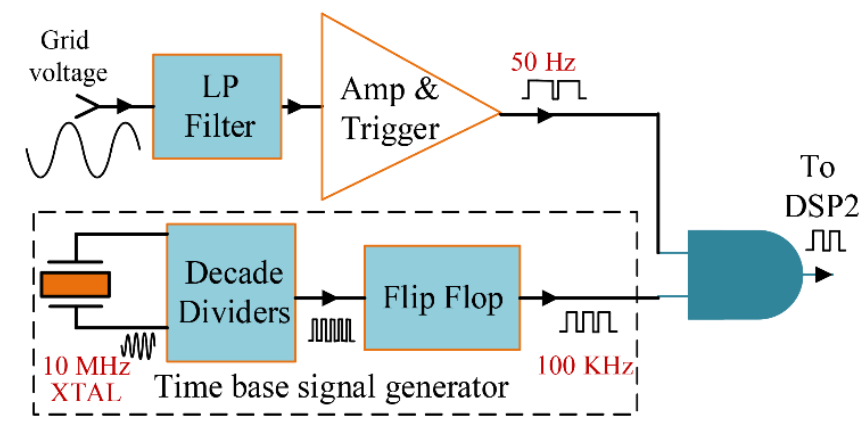

Figure 9 Frequency fault detection circuit

On the other hand, the reactive power is determined continuously by the instant value of the active power, considering the maximum available capacity of the inverter (determined based on output filter capacitors). The reason is that increasing reactive power may lead to an overmodulation and distortion in the output current due to the constant value of $V_{H V S}$. Therefore, the available reactive component of the output voltage $\left(V_{O-q}^{*}\right)$ is determined from

$$
V_{O-q}^{*}=\sqrt{V_{H V S}^{2}-V_{O-d}^{2}}
$$


where $V_{O-d}$ is the $d$ component of the output voltage. Along with the proposed control system for the inverter, proper fault detection circuits such as under and over frequency alarm signals have been implemented as presented in Figure 9 . The circuit provides a reaction time of less than $50 \mathrm{~ms}$ and an accuracy of $0.1 \%$ equal to $0.05 \mathrm{~Hz}$ by using the presented circuit.

\section{Experimental tests}

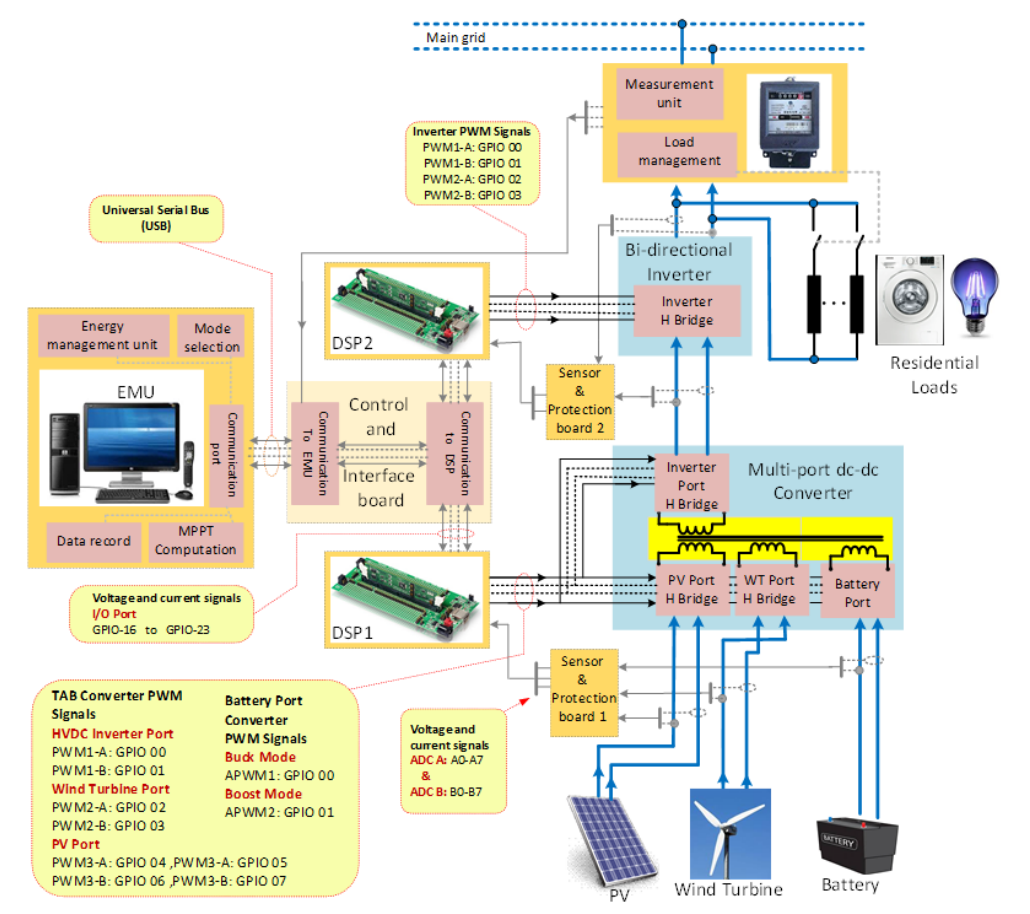

Figure 10 Block diagram of the experimentally developed hybrid renewable energy system

To validate the designed converter, a prototype of the proposed converter was developed in the lab. Figure 10 presents the overall block diagram of the developed hardware of the renewable energy system. Two DSP controllers (C2000/ TMS320F28335) made by Texas Instruments are used as local controllers to control the multiport phase shift dc-dc converter and the single-phase inverter as presented in Figure 11. A Laptop (Asus, FK003QM, CPU: Intel-core i7, 2.6G Hz, 12GB RAM) has been used as a master or global controller for energy management and data record and analysis. The Hall-Effect voltage (LV 25-P) and current (LTSR25-NP) sensors are used to measure the voltage and currents. The output voltage and currents of the single-phase inverter in different active and reactive power conditions is presented in the following figures. As can be seen in Figure 12 (a), the reactive power has been changed from 1.5 kVAR to $2.25 \mathrm{kVAR}$ and is of inductive type. However, the active power remained almost constant during the step change. The control system presented an acceptable performance to follow the applied step change. In Figure 12 (b), the reactive power injected to the utility grid by the inverter has been changed from inductive ( $2.55 \mathrm{kVAR})$ to the capacitive ( $2.54 \mathrm{kVAR})$ with an almost constant active power $(\approx 0.12 \mathrm{~kW})$. This shows the ability of the proposed converter in reactive power compensation and improvement of the utility grid parameters such as voltage and frequency in a limited range. To show the bidirectional power from the to/from the utility grid, the power flow from the inverter to the grid has been changed sharply changed to an opposite direction from the grid to the converter to charge the battery as illustrated 
in Figure 12 (c). In this case, the inverter is operated in the reverse direction as a rectifier and the energy transferred from the grid to the battery. This shows the ability of the proposed converter to be used as a virtual power plant and operate as an assistant to the utility grid and also provides benefits for the consumer. As can be seen the inverter is supplying $1.83 \mathrm{~kW}$ to the load and utility grid and then the active power is changed to the $1.73 \mathrm{~kW}$ in the reverse direction to charge the battery. The experimental test results show that the proposed system can be used successfully not only to supply the load but also to improve the utility grid performance.
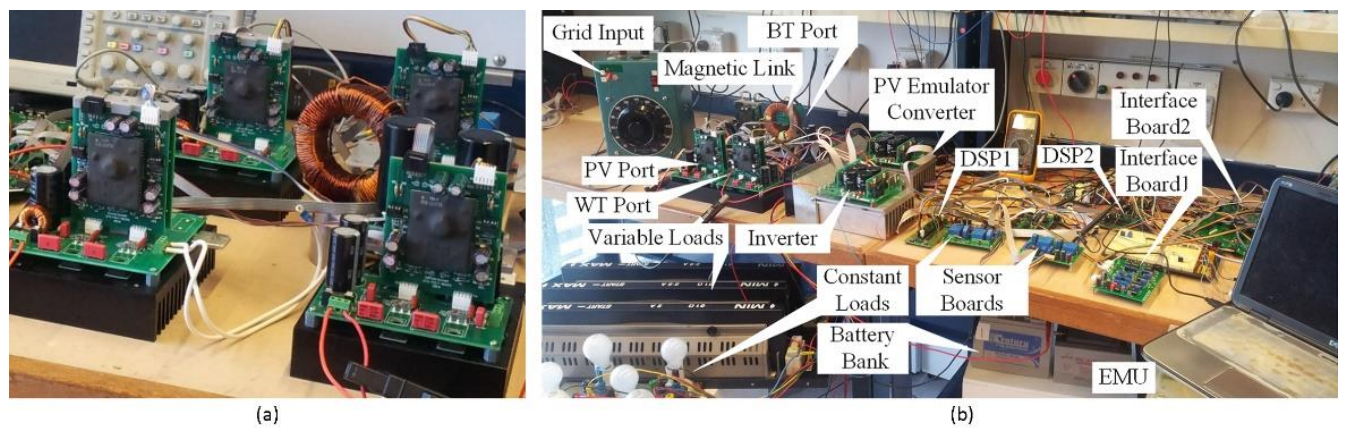

Figure 11 Experimentally developed system, (a) multiport dc-dc converter and, (b) renewable energy system and controllers

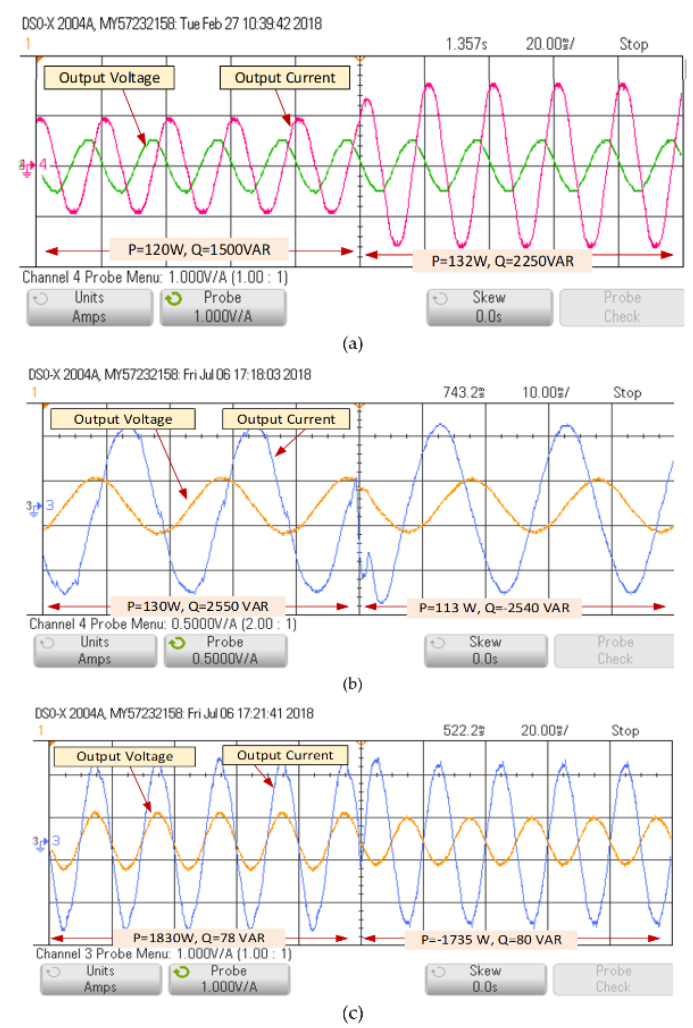

Figure 12 The experimental test results for power flow control, (a) the reactive power has been changed from 1.5 kVAR to 2.25 kVAR and is of inductive type, (b) the reactive power injected to the utility grid by the inverter has been changed from inductive ( 2.55 kVAR) to the capacitive (2.54 kVAR) and, (c) the inverter is supplying $1.83 \mathrm{~kW}$ to the load and utility grid and then the active power is changed to the $1.73 \mathrm{~kW}$ in the reverse direction to charge the battery. 


\section{Conclusions}

A multiport converter topology for integrating energies a PV system, a wind-turbine generator and a battery to supply a grid-connected domestic load has been presented in this paper, the operation principle and control technique of the proposed system analyzed in detail. The main advantage of the proposed system was using a multi-winding high-frequency transformer as a magnetic coupling between the converter ports. This resulted in the isolation of converter ports, easier voltage adaptation between the ports using transformer turns ratio, simpler power flow control based on the phase-shift technique compared to the conventional method of using common ac or dc bus. Therefore, the proposed topology can be a choice for future smart grid applications. However, the complexity of the transformer design limits the application for a higher number of energy converter ports. To validate the system topology and control technique, numerical simulations have been performed using PSIM software and the waveforms and the dynamic response of the system under a step-change in the load have been presented and analyzed and experimentally tested.

\section{Author Contributions}

Mohammad Jafari provided the main research idea and theoretical analysis and, Zahra Malekjamshidi contributed to the experimental test and software development.

\section{Competing Interests}

The authors confirm that there is not any conflict of interest related to this manuscript

\section{References}

1. Tao H, Duarte JL, Hendrix MA. Three-port triple-half-bridge bidirectional converter with zerovoltage switching. IEEE Trans Power Electron. 2008; 23: 782-92. DOI: 10.1109/TPEL.2007.915023.

2. Jafari M, Malekjamshidi Z, Zhu J. Design, analysis and control of a magnetically-coupled multiport multi-operation-mode residential micro-grid. Proceeding of the 2017 20th International Conference on Electrical Machines and Systems (ICEMS); 2017 August 11-14; Sydney, Australia. DOI: 10.1109/ICEMS.2017.8056449.

3. Al-Shetwi AQ, Hannan MA, Jern KP, Mansur M, Mahlia TM. Grid-connected renewable energy sources: Review of the recent integration requirements and control methods. J Clean Prod. 2020; 253: 119831.

4. Malekjamshidi Z, Jafari M, Imanieh M. Implementation of a full bridge series-parallel resonant dc-dc converter using ANN and SSM controllers. Proceedings of the 2011 IEEE National Aerospace and Electronics Conference (NAECON); 2011 July 20-22; Dayton, OH, USA. DOI: 10.1109/NAECON.2011.6183102.

5. Jafari M, Malekjamshidi Z, Zhu JG. Design, simulation and implementation of an intelligent MPPT using a ZVCS resonant DCDC converter. Proceeding of the 2012 IEEE International Conference on Power and Energy (PECon); 2012 December 2-5; Kota Kinabalu, Malaysia. DOI: 10.1109/PECon.2012.6450222. 
6. Duarte JL, Hendrix M, Simoes MG. Three-port bidirectional converter for hybrid fuel cell systems. IEEE Trans Power Electron. 2007; 22: 480-487. DOI: 10.1109/TPEL.2006.889928.

7. Ourahou M, Ayrir W, Hassouni BE, Haddi A. Review on smart grid control and reliability in presence of renewable energies: Challenges and prospects. Math Comput Simul. 2020; 167: 1931. DOI: $10.1016 /$ j.matcom.2018.11.009.

8. Malekjamshidi Z, Jafari M, Islam MR, Zhu J. A comparative study on characteristics of major topologies of voltage source multilevel inverters. Proceeding of the 2014 IEEE Innovative Smart Grid Technologies - Asia (ISGT ASIA); 2014 May 20-23; Kuala Lumpur, Malaysia. DOI: 10.1109/ISGT-Asia.2014.6873862.

9. Tao H, Kotsopoulos A, Duarte JL, Hendrix MA. Family of multiport bidirectional DC-DC converters. IEE Proc Electr Power Appl. 2006; 153: 451-458. DOI: 10.1049/ip-epa:20050362.

10. Liu YC, Chen YM. A systematic approach to synthesizing multiple-input dc-dc converter. IEEE Trans Power Electron. 2009; 24: 116-127. DOI: 10.1109/TPEL.2008.2009170.

11. Benavides ND, Chapman PL. Power budgeting of a multiple-input buck-boost converter. IEEE Trans Power Electron. 2005; 20: 1303-1309. DOI: 10.1109/tpel.2005.857531.

12. Dobbs BG, Chapman PL. A multiple-input DC-DC converter topology. IEEE Power Electron Lett. 2003; 1: 6-9. DOI: 10.1109/LPEL.2003.813481.

13. Jafari M, Hunter G, Zhu JG. A new topology of multi-input multi-output Buck-Boost DC-DC Converter for microgrid applications. Proceeding of the 2012 IEEE International Conference on Power and Energy (PECon); 2012 December 2-5; Kota Kinabalu, Malaysia. DOI: 10.1109/PECon.2012.6450223.

14. Duarte JL, Hendrix M, Simoes MG. Three-port bidirectional converter for hybrid fuel cell systems. IEEE Trans Power Electron. 2007; 22: 480-487.

15. Tao H, Kotsopoulos A, Duarte JL, Hendrix MA. Family of multiport bidirectional DC-DC converters. IEE Proc Electr Power Appl. 2006; 153: 451-458.

16. Tao $\mathrm{H}$. Integration of sustainable energy sources through power electronic converters in small distributed electricity generation systems. Eindhoven: Technische Universiteit Eindhoven; 2008.

17. Jafari M, Malekjamshidi Z, Zhu J. A magnetically coupled multiport, multi-operation-mode micro-grid with a predictive dynamic programming-based energy management for residential applications. Int J Electr Power Energy Syst. 2019; 104: 784-796. DOI: 10.1016/i.ijepes.2018.07.040.

18. Jafari M, Malekjamshidi Z, Islam MR, Zhu J. Modeling of magnetic flux in multi-winding toroidal core high frequency transformers using 3D reluctance network model. Proceeding of the 2015 IEEE 11th International Conference on Power Electronics and Drive Systems; 2015 June 9-12; Sydney, Australia. DOI: 10.1109/PEDS.2015.7203546

19. Jafari M, Malekjamshidi Z, Zhu J, Khooban M. Novel predictive fuzzy logic-based energy management system for grid-connected and off-grid operation of residential smart micro-grids. IEEE J Emerg Sel Top Power Electron. DOI: 10.1109/jestpe.2018.2882509.

20. Tao H, Kotsopoulos A, Duarte JL, Hendrix MA. Transformer-coupled multiport zvs bidirectional dc-dc converter with wide input range. IEEE Trans Power Electron. 2008; 23: 771-781. DOI: 10.1109/TPEL.2007.915129.

21. Jafari M, Malekjamshidi Z, Zhu J. Copper loss analysis of a multiwinding high-frequency transformer for a magnetically-coupled residential microgrid. IEEE Trans Ind Appl. 2019; 55: 283-297. DOI: 10.1109/TIA.2018.2864170. 
22. Barrios EL, Ursúa A, Marroyo L, Sanchis P. Analytical Design Methodology for Litz-Wired HighFrequency Power Transformers. IEEE Trans Ind Electron. 2015; 62: 2103-2113.

23. Jafari M, Malekjamshidi Z, G. Lei, T. Wang, Platt G, Zhu J. Design and implementation of an amorphous high-frequency transformer coupling multiple converters in a smart microgrid. IEEE Trans Ind Electron. 2017; 64: 1028-1037. DOI: 10.1109/TIE.2016.2583401.

24. Jafari M, Malekjamshidi Z, Zhu J. Design and development of a multi-winding high-frequency magnetic link for grid integration of residential renewable energy systems. Appl Energ. 2019; 242: 1209-1225. DOI: 10.1016/j.apenergy.2019.03.124.

25. Chen YM, Liu YC, Wu FY. Multi-input DC/DC converter based on the multiwinding transformer for renewable energy applications. IEEE Trans Ind Appl. 2002; 38: 1096-1104. DOI: 10.1109/TIA.2002.800776.

26. Michon M, Duarte JL, Hendrix M, Simoes MG. A three-port bi-directional converter for hybrid fuel cell systems. Proceeding of the IEEE Power Electronics Specialists Conference (PESC'04); 2004 June 20-25; Aachen, Germany. DOI: 10.1109/PESC.2004.1354836.

27. Zhao C, Kolar JW. A novel three-phase three-port UPS employing a single high-frequency isolation transformer. Proceeding of the IEEE Power Electronics Specialists Conference (PESC'04); 2004 June 20-25; Aachen, Germany. DOI: 10.1109/PESC.2004.1354730

28. Jafari M, Malekjamshidi Z, Lu DD, Zhu J. Development of a Fuzzy-Logic-Based energy management system for a multiport multioperation mode residential smart microgrid. IEEE Trans Power Electron. 2019; 34: 3283-3301. DOI: 10.1109/tpel.2018.2850852.

29. Jafari M, Platt G, Malekjamshidi Z, Zhu JG. Technical issues of sizing Lead-Acid batteries for application in residential renewable energy systems. Proceeding of the 2015 4th International Conference on Electric Power and Energy Conversion Systems (EPECS); 2015 November 24-26; Sharjah, United Arab Emirates. DOI: 10.1109/epecs.2015.7368533.

30. Liu D, Li H. A ZVS bi-directional DC-DC converter for multiple energy storage elements. IEEE Trans Power Electron. 2006; 21: 1513-1517. 2006. DOI: 10.1109/TPEL.2006.882450.

31. Jafari M, Malekjamshidi Z, Li L, Zhu JG. Performance analysis of full bridge, boost half bridge and half bridge topologies for application in phase shift converters. Proceeding of the 2013 International Conference on Electrical Machines and Systems (ICEMS); 2013 October 26-29; Busan, South Korea. DOI: 10.1109/ICEMS.2013.6713326.

32. Jafari M, Malekjamshidi Z, Platt G, Zhu JG, Dorrell DG. A multiport converter based renewable energy system for residential consumers of smart grid. Proceeding of the IECON 2015 - 41st Annual Conference of the IEEE Industrial Electronics Society; 2015 November 9-12; Yokohama, Japan. DOI: 10.1109/iecon.2015.7392911.

33. Shi Y, Li R, Xue Y, Li H. High-frequency-link-based grid-tied PV system with small DC-link capacitor and low-frequency ripple-free maximum power point tracking. IEEE Trans Power Electron. 2016; 31: 328-339. DOI: 10.1109/tpel.2015.2411858.

34. Chen G, Xu D, Wang Y, Lee Y. A new family of soft-switching phase-shift idirectional DC-DC converters. Proceeding of the IEEE Power Electronics Specialists Conference (PESC'01); 2001 June 17-21; Vancouver, Canada. DOI: 10.1109/PESC.2001.954227.

35. Jafari M, Islam MR, Malekjamshidi Z, Zhu J. Modeling of multi-winding high-frequency transformers as a common magnetic-link in smart micro-grids. Proceeding of the 2015 International Conference on Electrical \& Electronic Engineering (ICEEE); 2015 November 4-6; Rajshahi, Bangladesh. DOI: 10.1109/ceee.2015.7428269. 
36. Kheraluwala MN, Gascoigne RW, Divan DM, Baumann ED. Performance characterization of a high-power dual active bridge DC-to-DC converter. IEEE Trans Ind Appl. 1992; 28: 1294-1301. DOI: $10.1109 / 28.175280$.

37. Vangen K, Melaa T, Bergsmark S, Nilsen R. Efficient high-frequency soft-switched power converter with signal processor control. Proceeding of the IEEE Telecommunications Energy Conference (INTELEC'91); 1991 November 5-8; Kyoto, Japan.

38. Vangen K, Melaa T, Adnanes AK. Soft-switched high-frequency, high power DC/AC converter with IGBT. Proceeding of the IEEE Power Electronics Specialists Conference (PESC'92); 1992 June 29-July 3; Toledo, Spain.

39. Vangen K, Melaa T, Adnanes AK, Kristiansen PE. Dual active bridge converter with large softswitching range. Proceeding of the Fifth European Conference on Power Electronics and Applications (EPE'93); 1993 September 13-16; Brighton, UK.

40. Zhang JM, Xu DM, Qian Z. An improved dual active bridge DC/DC converter, IEEE Power Electronics Specialists Conference (PESC'01); 2001 June 17-21; Vancouver, Canada. DOI: 10.1109/pesc.2001.954025.

41. Zhang J, Zhang F, Xie X, Jiao D, Qian Z. A novel ZVS DC/DC converter for high power applications. IEEE Trans Power Electron. 2004; 19: 420-429. DOI: 10.1109/TPEL.2003.823248.

42. Jafari M, Malekjamshidi Z, Zhu JG. Analysis of operation modes and limitations of dual active bridge phase shift converter. Proceeding of the 2015 IEEE 11th International Conference on Power Electronics and Drive Systems; 2015 June 9-12; Sydney, Australia. DOI: 10.1109/PEDS.2015.7203545.

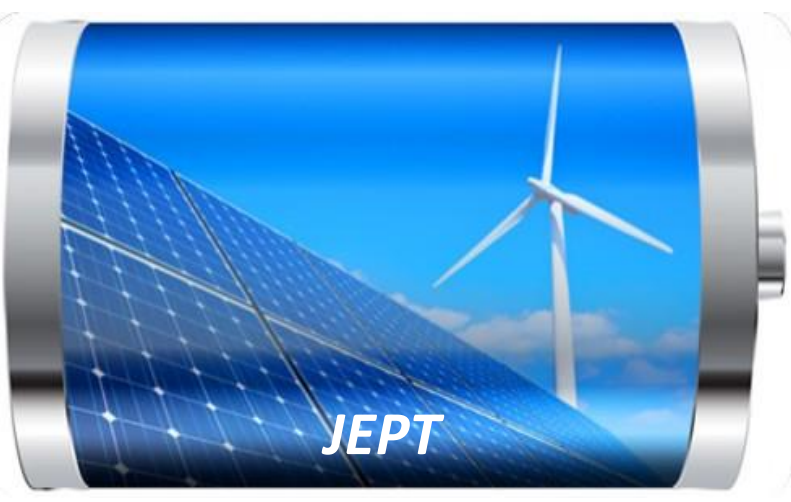

Enjoy JEPT by:

1. Submitting a manuscript

2. Joining in volunteer reviewer bank

3. Joining Editorial Board

4. Guest editing a special issue

For more details, please visit:

http://www.lidsen.com/journal/jept 